\title{
Avaliação do efeito antidepressivo símile in vivo de um derivado de chalcona e sua modelagem molecular por docking
}

\author{
Evaluation of the similar antidepressant effect in vivo of a chalcone derivative and its \\ molecular modeling by docking
}

\section{Evaluación del efecto antidepresivo similar in vivo de un derivado de chalcona y su modelado molecular mediante acoplamento}

Kardilandia Mendes de Oliveira ${ }^{1 *}$, Caliandra Maria Bezerra Luna Lima ${ }^{1}$, Cinthia Rodrigues Melo, Abrahão Alves de Oliveira Filho², Flávio Valadares Pereira Borges ${ }^{1}$, Gabrielly Diniz Duarte ${ }^{1}$, Luis Cezar Rodrigues ${ }^{1}$, Humberto Hugo Nunes de Andrade ${ }^{1}$, Álefe Brito Monteiro ${ }^{1}$, Liana Clébia de Morais Pordeus ${ }^{1}$.

\section{RESUMO}

Objetivo: Investigar a substância GA-4, quanto a ser um potente candidato a antidepressivo, além de identificar seu possível mecanismo de ação através de docking. Métodos: Foram realizados ensaios psicofarmacológicos in vivo, devidamente autorizado pelo Comitê de ética no uso de animais, utilizando camundongos Swiss, sendo através de testes do campo aberto nas doses de 50, 100 e $200 \mathrm{mg} / \mathrm{Kg}$, analisando os parâmetros: Rearing, Grooming, Número de cruzamentos, micções e bolos fecais. Além do teste do nado forçado, sendo avaliado o tempo de imobilidade dos animais nas mesmas doses do teste de campo aberto. A modelagem molecular foi realizada através de programas computacionais. Resultados: Os resultados mostraram que a substância GA-4 apresenta atividade antidepressiva, tendo em vista que reduziu o tempo de imobilidade no teste do nado forçado e não alterou a atividade locomotora no teste de campo aberto. No estudo de docking, a substância GA-4 teve afinidade com o receptor a2- adrenérgico e se ligou no mesmo sítio de ativação da ioimbina, mostrando ser um possível antagonista dos receptores a2- adrenérgico Conclusão: Diante dos resultados obtidos, podemos concluir que a substância GA-4 é um potencial candidato a medicamento antidepressor. Possivelmente por antagonizar os receptores a2- adrenérgico.

Palavras-chave: Antidepressivo, Docking, Antagonista adrenérgico.

\begin{abstract}
Objective: Investigate the substance GA-4, as to be a potent antidepressant candidate, in addition to identifying its possible mechanism of action through docking. Methods: Psychopharmacological tests were carried out in vivo, duly authorized by the Ethics Committee on the use of animals, using Swiss mice, using open field tests at doses of 50, 100 and $200 \mathrm{mg} / \mathrm{Kg}$, analyzing the parameters: Rearing, Grooming, Number of crossings, urination and faecal cakes. In addition to the forced swimming test, the immobility time of the animals was evaluated at the same doses as the open field test. Molecular modeling was performed using computer programs. Results: The results showed that the substance GA-4 has antidepressant activity, since it reduced the immobility time in the forced swim test and did not alter the locomotor activity in the open field test. In the docking study, the substance GA-4 had an affinity for the $\alpha 2$-adrenergic receptor and bound in the same activation site of yohimbine, showing to be a possible antagonist of a2-adrenergic receptors. Conclusion: In view of the results obtained, we can conclude that the substance GA-4 is a potential candidate for antidepressant medication. Possibly by antagonizing a2-adrenergic receptors.
\end{abstract}

Key words: Antidepressant, Docking, Adrenergic antagonist.

\section{RESUMEN}

Objetivo: Investigue la sustancia GA-4, como un candidato antidepresivo potente, además de identificar su posible mecanismo de acción a través del acoplamiento. Métodos: Las pruebas psicofarmacológicas se llevaron a cabo in vivo, debidamente autorizadas por el Comité de Ética sobre el uso de animales, usando ratones suizos, usando pruebas de campo abierto a dosis de 50, 100 y $200 \mathrm{mg} / \mathrm{Kg}$, analizando los parámetros: Crianza, Aseo, Número de cruces, micción y pasteles fecales. Además de la prueba de natación forzada, se evaluó el tiempo de inmovilidad de los animales a las mismas dosis que la prueba de campo

${ }^{1}$ Universidade Federal da Paraíba (UFPB), João Pessoa - PB. *E-mail: kardymendes@bol.com.br

2 Universidade Federal de Campina Grande (UFCG), Campina Grande - PB. 
abierto. El modelado molecular se realizó mediante programas informáticos. Resultados: Los resultados mostraron que la sustancia GA-4 tiene actividad antidepresiva, considerando que redujo el tiempo de inmovilidad en la prueba de natación forzada y no alteró la actividad locomotora en la prueba de campo abierto. En el estudio de acoplamiento, la sustancia GA-4 tenía afinidad por el receptor adrenérgico $\alpha 2$ y se ligó en el mismo sitio de activación de la yohimbina, lo que demuestra que es un posible antagonista de los receptores adrenérgicos a2. Conclusión: En vista de los resultados obtenidos, podemos concluir que la sustancia GA-4 es un candidato potencial para la medicación antidepresiva. Posiblemente antagonizando los receptores adrenérgicos $\alpha 2$.

Palabras clave: Antidepresivo, Acoplamiento, Antagonista adrenérgico.

\section{INTRODUÇÃO}

A depressão é um dos principais transtornos do sistema nervoso, e que acomete grande parte da população, tornando muitas vezes o paciente incapaz de realizar certas atividades. Portanto, a busca por novas drogas que possam agir mais efetivamente e com menos efeitos adversos, tem sido uma busca constante (MÉNARD C, et al., 2016; WANG J, et al., 2017).

As chalconas são uma classe química importante na química medicinal por mostrar muitas atividades biológicas interessantes, além de uma síntese conveniente (GOMES MN, et al., 2017; ZHUANG C, et al., 2017). São relatadas diferentes atividades farmacológicas, que as chalconas possuem, como: ações antiinflamatórias, antimicrobianas, antioxidantes, citotóxicas, antitumorais entre outras. Além disso, testes mostram que as chalconas são promissoras para o desenvolvimento de novos fármacos com ação no Sistema Nervoso Central (SNC), como para o tratamento da depressão (GUAN LP, et al., 2014; HIGGS J, et al., 2019). Diante disso, foi sintetizado a substância 3-(benzo[d][1,3]dioxol-5-il)-5-(tiofen-2-il)-4,5-dihidro-1 H-pirazol-1carbotioamida, que é uma chalcona, também conhecida como GA-4. Tendo em vista ser uma substância nova, sem nenhuma atividade farmacológica estudada, foi investigado se esta apresentava atividade antidepressiva.

O mecanismo patológico da depressão, bem como a investigação de novos candidatos a antidepressivos, podem ser realizados através de ensaios de modelagem molecular, e estudos in vivo por meio de testes comportamentais (HAO Y, et al., 2019). Através de Docking é possível prever o acoplamento de moléculas à sua proteína alvo; além de ser uma ferramenta de grande utilidade no desenvolvimento de medicamentos, é possível utilizá-la para avaliar se a substância em estudo consegue ligar-se à proteína, e se isso ocorre no sítio ativo (PAGADALA NS, et al., 2017). O docking é uma ferramenta bem utilizada para prever possíveis acoplamentos de antidepressivos e diferentes proteínas alvo, sendo comumente realizado estudos in silico associados com ensaios in vivo, buscando novas ações de tais medicamentos (DAWOOD S, et al., 2014; BASHIR MA, et al., 2019).

Os testes in vivo para avaliação psicofarmacológica podem ser: teste do nado forçado (UNAL G e CANBEYLI R, 2019), suspensão da cauda, campo aberto, preferência por sacarose, dentre outros (HAO J, et al., 2019; POLESZAK E, et al., 2019). O teste de nado forçado fornece uma visão da resposta ao estresse, o qual é um fator que contribui para depressão em humanos, e a depressão está relacionada à resposta alterada ao estresse (COMMONS KG, et al., 2017). O teste do campo aberto avalia a atividade locomotora do animal, de forma que quando reduzida, indica comportamentos semelhantes à ansiedade associados à depressão.

Portanto o objetivo do estudo foi nvestigar a substância GA-4, quanto a ser um potente candidato a antidepressivo, além de identificar seu possível mecanismo de ação através de docking.

\section{MÉTODOS}

A preparação da substância GA-4 ocorreu da seguinte forma: em um tubo de reação foram adicionados a chalcona tiofênica (2 mMol), tiossemicarbazida (1,75 mMol) e hidróxido de sódio (2 mMol) e solubilizados em $25 \mathrm{~mL}$ de etanol absoluto. A reação foi mantida sob refluxo por 24 horas e durante esse tempo ocorreu a precipitação de um sólido branco. Uma vez que não há mais chalcona na reação, o sólido foi filtrado e o sobrenadante concentrado para aumentar a precipitação do produto. $O$ sólido branco obtido foi seco em dessecador e pesado posteriormente. 
A caracterização da substância GA-4, foi feita por meio de análise de Ressonância Magnética Nuclear (Ascend ${ }^{\mathrm{TM}}$ 400, Bruker) em solvente deuterado adequado (clorofórmio) em concentrações de $100 \mathrm{mg} / \mathrm{mL}$. O ponto de fusão foi medido em equipamento digital modelo PFD III (Marte Científica) utilizando capilares de vidro e termômetro de mercúrio em temperaturas de até $300 \stackrel{\circ}{\circ}$.

Para os estudos psicofarmacológicos foram utilizados 40 camundongos Swiss ,os quais foram fornecidos pela Unidade de Produção Animal (UPA) do Instituto de Pesquisa em Fármacos e Medicamentos (IPeFarM), UFPB, Brasil. Todos os animais foram agrupados em gaiolas de polietileno medindo $49 \times 34 \mathrm{X} 16 \mathrm{~cm}$ contendo até 3 animais. Foram mantidos sob condições controladas de temperatura de $22 \pm 3^{\circ} \mathrm{C}$, em ciclos de claro e escuro de 12 horas ( $6 \mathrm{~h} 00$ às $18 \mathrm{~h} 00$ claro e das $18 \mathrm{~h} 00$ às $6 \mathrm{~h} 00$ escuro) com livre acesso à água e a uma dieta controlada, a base de ração do tipo pellets durante todo o período de experimentação, e sem uso de qualquer medicamento. Os procedimentos experimentais foram analisados e aprovados pelo Comitê de Ética em Pesquisa Animal (CEUA) da UFPB protocolo $\mathrm{N}^{\circ}$ 041/2015. A eutanásia dos animais foi realizada por sobredose de solução anestésica contendo $300 \mathrm{mg} / \mathrm{Kg}$ de Cetamina e $30 \mathrm{mg} / \mathrm{Kg}$ de Xilasina, sendo administrado por via intraperitoneal (IP).

Foi realizado o ensaio psicofarmacológico, utilizando como parâmetros: teste do campo aberto e nado forçado. O campo aberto é um instrumento de vidro transparente e piso preto ( $30 \times 30 \times 15 \mathrm{~cm})$, como uma arena circular dividida em nove quadrantes iguais (ARCHER J, 1973). Hall CS (1934), desenvolveu este teste para investigar o efeito causado sobre a emocionalidade aos ratos, quando expostos a um ambiente novo, podendo assim ser avaliado o potencial ansiolítico de drogas.

Foram utilizados cinco grupos, contendo 8 camundongos cada: sendo 3 grupos tratados com a substância GA-4 nas doses de 50, 100 e $200 \mathrm{mg} / \mathrm{Kg}$, i.p; um grupo tratado com Imipramina $(30 \mathrm{mg} / \mathrm{Kg})$ e um grupo controle que recebeu o veículo. Após 30 minutos da administração, os animais foram colocados no centro da arena para explorar o ambiente livremente por um período de 5 minutos. Foram observados os seguintes parâmetros: número de vezes que o animal se levantou (Rearing), número de vezes de autolimpeza (Grooming), ambulação (número de cruzamentos dos segmentos pelo animal com as quatro patas, número de bolos fecais, e micção (MONTGOMERY KC, 1955; LEITE JR e SIQUEIRA JS, 2006).

Para realização do teste de nado forçado, foi utilizado um cilindro de acrílico transparente, medindo $18 \mathrm{~cm}$ de altura e $14 \mathrm{~cm}$ de diâmetro, com volume total de $2 \mathrm{~L}$, contendo $1,5 \mathrm{~L}$ de água a $27^{\circ} \mathrm{C}$.

Os animais foram divididos em cinco grupos com 8 animais cada. Sendo: três grupos tratados com a substância G-4 (50, 100 e $200 \mathrm{mg} / \mathrm{Kg}$ ), um grupo recebeu Imipramina na dose de $30 \mathrm{mg} / \mathrm{Kg}$, e um grupo controle que recebeu o veículo. Após o intervalo aproximado de 35 minutos da administração (30 minutos após o tratamento + 5 minutos da observação no campo aberto), cada animal foi colocado para nadar individualmente no cilindro por 5 minutos, tempo durante o qual foi observado o tempo de imobilidade (em minutos), sendo assim avaliado o efeito da droga neste teste experimental. O estado de imobilidade comportamental facilmente identificável foi descrito como o estado de "desespero" quando o animal percebe que a fuga é impossível e desiste (desespero comportamental) (PORSOLT RD, et al., 1978).

Também foi realizado a modelagem molecular (Docking). No Protein Data Bank (PDB) foi obtida a estrutura cristalográfica das proteínas no formato PDB para sua utilização nos programas AutoDockVina e AutoDockTools. Foi obtido o receptor a2-adrenérgico e seu antagonista ioimbina (código PDB 6K41). As substâncias-testes utilizadas foram desenhadas no Chem Draw (v.18.0), exportadas no formato SDF e posteriormente transformadas no formato PDB utilizando o software PyMol. O arquivo da proteína obtido no PDB foi processado no AutoDockTools para remoção de ligantes e adição de hidrogênios polares, gerando um arquivo PDBQT, necessário para os cálculos do AutoGrid. O mesmo foi feito para os ligantes que foram gravados na extensão PDBQT na opção Save as PDBQT do software.

Utilizando ainda a ferramenta AutoDockTools com a proteína-alvo, no menu Grid, foi definido o espaço tridimensional no qual o ligante pode se ligar à proteína. $O$ valor definido nas opções do Grid Box para as coordenadas x, y e z foram 76, 126 e 126, respectivamente. Estes valores foram inseridos no arquivo de configurações do docking para ser utilizado no AutoDockVina. O docking foi feito em linha de comando na 
pasta contendo todos os arquivos necessários através do comando "vina --config conf.txt --log logSO.txt". O processo foi repetido duas vezes para obter-se os resultados dos dois ligantes testados. O arquivo PDBQT gerado foi visualizado no PyMol para obtenção das poses.

A análise estatística dos resultados in vivo, foi realizada através do programa GraphPad Prism, versão 6.0. Inicialmente foi avaliada a distribuição dos dados, através do Teste de Kolmogorov-Smirnov, afim de definir a adequação do uso de testes paramétricos ou não-paramétricos, Kruskal-Wallis, seguido também pelo teste D'Agostino \& Pearson. Foi considerado como significativo os testes que apresentaram nível de significância menor que $5 \%$ ( $p$-valor $<0,05)$. Ressalta-se ainda que os resultados foram expressos em média e erro padrão da média (e.p.m.) ou desvio padrão da média.

\section{RESULTADOS}

A Caracterização da 3-(benzo[d][1,3]dioxol-5-il)-5-(tiofen-2-il)-4,5-dihidro-1H-pirazol-1-carbotioamida (GA04) foi feito através de RMN. A ga-04 apresenta-se como um sólido branco, PF 160-163 ํㅜ ; rendimento $59,60 \% ;{ }^{1} \mathrm{H}$ RMN (400 MHz, $\mathrm{CDCl}_{3}$ ) $\delta 3,32$ (dd, J 17,4; $2,9 \mathrm{~Hz}, 1 \mathrm{H}, \mathrm{H} 2 \mathrm{a}$ '), 3,75 (dd, J 17,4; 10,9 Hz, $1 \mathrm{H}, \mathrm{H} 2 \mathrm{a}$ ), 6,04 (s, 2H, - $\mathrm{OCH}_{2} \mathrm{O}-$ ), 6,34 (ddd, J 10,9; 3,0; 0,7 Hz, 1H, H3a), 6,85 (dd, J 8,2; 0,4 Hz, 1H, H5'), 6,93 (dd, J 5,1; 3,5 Hz, 1H, H4), 7,05 (ddd, J 3,5; 1,3; 0,7 Hz, 1H, H5), 7,14 (dd, J 8,1; 1,7 Hz, 1H, H6'), 7,19 (dd, J 5,1; $1,2 \mathrm{~Hz}, 1 \mathrm{H}, \mathrm{H} 3$ ), 7,34 (d, J 1,7 Hz, 1H, H2'). $\left.{ }^{13} \mathrm{C} \mathrm{RMN} \mathrm{(101} \mathrm{MHz,} \mathrm{CDCl}\right) \delta ~ 43,10$ (C2a), 59,29 (C3a), 101,90 (-OCH${ }_{2} \mathrm{O}-$ ), 106,52 (C2'), 108,56 (C5'), 122,64 (C6'), 124,38 (C4), 124,86 (C1), 125,12 (C3), 126,89 (C5), 144, 15 (C1'), 148,52 (C3'), 150,47 (C4'), 156,03 (C1a), 176,46 (C6a).

O RMN ${ }^{1} \mathrm{H}$ do composto GA-04 não mostrou nenhum sinal referente aos hidrogênios da insaturação $\alpha \beta$ presente na chalcona, confirmando a cicloadição entre a chalcona e a tiossemicarbazida para formar 0 composto desejado. Ainda, o anel pirazólico teve sua estrutura elucidada com a insaturação na posição 1a, uma vez que os hidrogênios na posição $2 a$ apareceram como duplos dubletos a $\delta 3,32(J 17,4 ; 2,9 \mathrm{~Hz}), 3,75$ $(J 17,4 ; 10,9 \mathrm{~Hz}) \mathrm{ppm}$, respectivamente; configurando assim, o acoplamento geminal destes hidrogênios a $17,4 \mathrm{~Hz}$. O hidrogênio na posição 3a aparece como um duplo, duplo dubleto a $\delta 6,34(\mathrm{~J} 10,9 ; 3,0 ; 0,7 \mathrm{~Hz})$ ppm, acoplando a três ligações com os dois hidrogênios na posição $2 a$, o que é constatado quando se observa as constantes de acoplamento a 10,9 e 3,0 Hz, respectivamente (Figura 1).

Figura 1 - Espectro RMN ${ }^{1} \mathrm{H} 400 \mathrm{MHz}$ de GA-04.

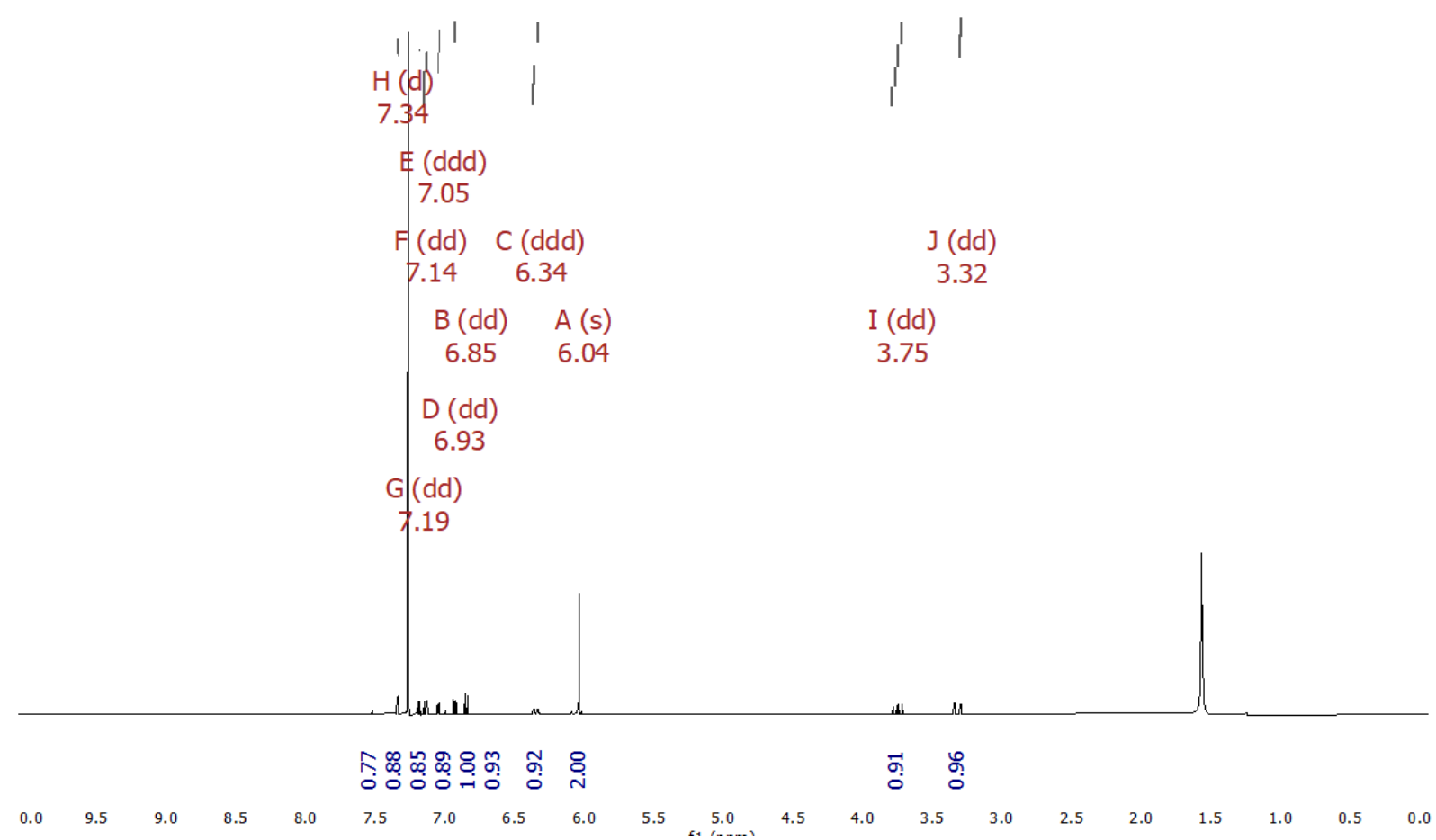

Fonte: Oliveira KM, et al., 2020. 
Foram geradas 3 poses de interação de GA-04 com a proteína. No qual todas as poses apresentaram energias de ligação aproximadas, sendo a pose 1 a que teve melhor afinidade com o receptor a2- adrenérgico, até mesmo quando comparada com a sustância padrão ioimbina (código PDB 6K41) (Tabela 1). Além disso foi observado que a GA-04 se ligou no mesmo sítio de ativação da ioimbina, mostrando ser um possível antagonista dos receptores a2- adrenérgico (Figura 2).

Tabela 1 - Energia de ligação da substância GA-04 com o receptor a2- adrenérgico em comparação com o padrão ioimbina.

\begin{tabular}{cccc} 
Ligante & Pose 1 & Pose 2 & Pose 3 \\
loimbina & -7.8 & -7.3 & -7.3 \\
GA-04 & -7.9 & -7.8 & -7.6 \\
\hline
\end{tabular}

Fonte: Oliveira KM, et al., 2020.

Figura 2 - Interação da substância GA-04 com o receptor a2- adrenérgico no mesmo sítio de ativação da ioimbina.

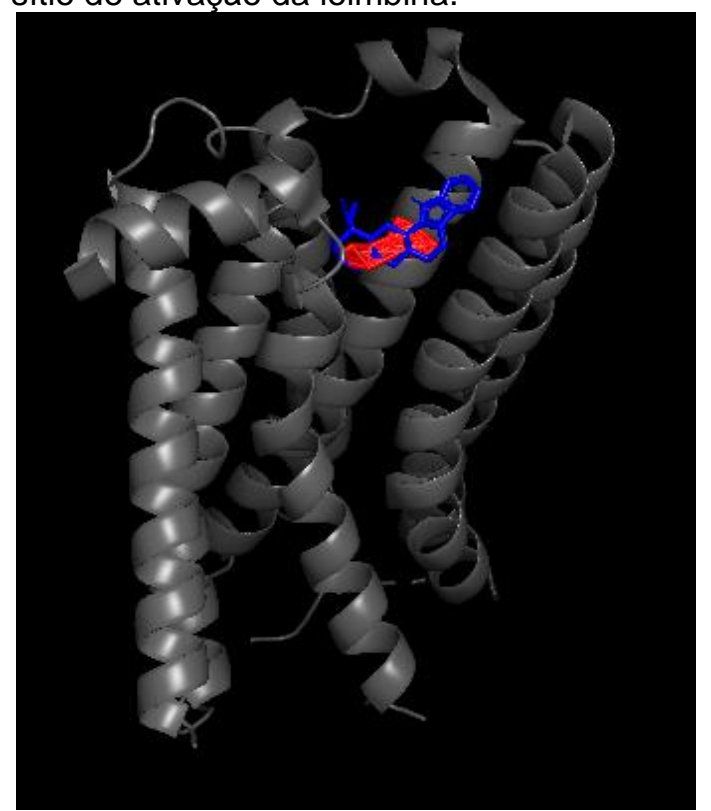

Legenda: Proteína em cinza, GA-04 em vermelho e ioimbina em Azul.

Fonte: Oliveira KM, et al., 2020.

Os animais tratados com a substância GA-4 nas doses de 50, 100 e $200 \mathrm{mg} / \mathrm{Kg}$, foram submetidos ao teste do Campo Aberto, sendo por meio deste, avaliados cinco parâmetros. Os grupos tratados com a substância GA-4, foram comparados com o grupo controle negativo (que recebeu o veículo) (Tabela 2).

Tabela 2 - Avaliação do efeito da substância GA-4 nas doses de 50, 100 e 200 mg/Kg sobre o Sistema Nervoso no Teste do Campo Aberto.

\begin{tabular}{cccccc}
\hline- & Controle & $\begin{array}{c}\text { Imipramina } \\
\mathbf{3 0 ~} \mathbf{~ g} / \mathbf{K g}\end{array}$ & $\begin{array}{c}\mathbf{G A}-4 \\
\mathbf{5 0} \mathbf{~} \mathbf{g} / \mathbf{K g}\end{array}$ & $\begin{array}{c}\text { GA-4 } \\
\mathbf{1 0 0} \mathbf{~} \mathbf{~ g} / \mathbf{K g}\end{array}$ & $\mathbf{2 0 0} \mathbf{~} \mathbf{~ g} / \mathbf{K g}$ \\
\hline Levantar & $31 \pm 4,6$ & $30,3 \pm 2,6$ & $40,3 \pm 4,0$ & $33,1 \pm 4,6$ & $44,4 \pm 4,1$ \\
Autolimpeza & $2,8 \pm 0,9$ & $1,6 \pm 0,2$ & $2,0 \pm 0,3$ & $2,5 \pm 0,4$ & $2,3 \pm 0,9$ \\
Cruzamentos & $97,9 \pm 6,5$ & $78,6 \pm 2,7$ & $107,3 \pm 6,5^{\mathrm{b}}$ & $76,7 \pm 4,5$ & $114,5 \pm 7,1^{\mathrm{b}}$ \\
Micções & $0,1 \pm 0,1$ & $0,3 \pm 0,3$ & $0,6 \pm 0,2$ & $0,8 \pm 0,4$ & $2,3 \pm 0,7 \mathrm{a}$ \\
Bolos Fecais & $2,0 \pm 0,7$ & $0,9 \pm 0,4$ & $1,0 \pm 0,3$ & $0,8 \pm 0,4$ & $2,3 \pm 0,7$ \\
\hline
\end{tabular}

Nota: Os resultados estão expressos como média \pm erro padrão da média. Análise por Kruskal-Wallis, seguido também pelo teste D'Agostino \& Pearson. Legenda: a $p<0,05$ comparado com grupo controle; ${ }^{b} p<0,05$ comparado com grupo imipramina (30 mg/kg). Fonte: Oliveira KM, et al., 2020. 
No parâmetro exploratório de levantar (Rearing) não foi observado nenhuma alteração significativa dos grupos tratados por GA-4 comparados com o grupo controle. O mesmo resultado foi encontrado com o parâmetro de autolimpeza (Grooming).

Ao analisarmos o número de cruzamentos dos animais, verificamos que não houve nenhuma alteração estatisticamente significativa quando comparamos com o grupo controle. Já ao comparar com a Imipramina (30 mg/Kg), observa-se um aumento da mobilidade dos animais que foram tratados nas doses de 50 e 200 $\mathrm{mg} / \mathrm{Kg}$. A partir dos resultados obtidos, a substância GA-4 não alterou a locomoção dos animais, logo não apresenta ser uma substância psicoestimulante.

Também foi avaliado a atividade autonômica dos animais quanto a micção e quantidade de bolos fecais. Os animais tratados com a dose de $200 \mathrm{mg} / \mathrm{Kg}$, apresentaram um maior número de micções ao ser comparado com o grupo controle. Já quanto ao número de bolos fecais, não houve nenhuma alteração significativa dos grupos tratados por GA-4 em relação ao controle. Tais resultados refletem a emocionalidade dos animais, e consequentemente seu estado de ansiedade. Podemos inferir, portanto que a substância GA-4 não causou um aumento de ansiedade dos animais, já que não ocorreram alterações significativas com relação ao grupo controle.

Assim, a partir dos resultados do teste de campo aberto, a substância GA-4, apresenta ser uma substância antidepressiva, já que mostrou resultados aproximados aos da Imipramina, que é um medicamento antidepressivo amplamente utilizado na clínica; além do que a substância GA-4 não apresentou ser psicoestimulante e nem ansiolítica.

Através do teste do nado forçado, foi possível observar que os animais tratados com a substância GA-4 nas doses de 50 e $100 \mathrm{mg} / \mathrm{Kg}$, e os que receberam Imipramina (30 mg/Kg), tiveram uma diminuição do tempo de imobilidade comparado com o grupo controle. Já o grupo que recebeu a maior dose $(200 \mathrm{mg} / \mathrm{Kg})$, não apresentou nenhuma alteração significativa comparada com o controle, mas obteve um aumento do tempo de imobilidade comparado com o grupo que recebeu Imipramina. Desta forma sugere-se um possível efeito antidepressivo da substância estudada nas doses de $50 \mathrm{mg} / / \mathrm{Kg}$ e $100 \mathrm{mg} / \mathrm{Kg}$ (Tabela 3).

Este resultado corrobora com os resultados do teste de campo aberto. No qual a substância GA-4, por não ocasionar alterações na locomoção dos animais, e diminuir o tempo de imobilidade no teste de nado forçado, mostra ser esta uma substância com característica antidepressora.

Tabela 3 - Avaliação do efeito da substância GA-4 nas doses de 50, 100 e 200 mg/Kg sobre o Sistema Nervoso no Teste do Nado Forçado.

\begin{tabular}{cccccc}
\hline- & Controle & $\begin{array}{c}\text { Imipramina } \\
\mathbf{3 0} \mathbf{~ m g / K g}\end{array}$ & $\begin{array}{c}\text { GA-4 } \\
\mathbf{5 0} \mathbf{~ m g} / \mathbf{K g}\end{array}$ & $\begin{array}{c}\mathbf{G A}-\mathbf{4} \\
\mathbf{1 0 0} \mathbf{~ m g} / \mathbf{K g}\end{array}$ & $\begin{array}{c}\mathbf{G A}-\mathbf{4} \\
\mathbf{2 0 0} \mathbf{~ m g} / \mathbf{K g}\end{array}$ \\
\hline $\begin{array}{c}\text { Tempo de } \\
\text { imobilidade (m) }\end{array}$ & $2,3 \pm 0,1$ & $0,8 \pm 0,2^{\mathrm{a}}$ & $0,7 \pm 0,1^{\mathrm{a}}$ & $0,8 \pm 0,2^{\mathrm{a}}$ & $2,2 \pm 0,3^{\mathrm{b}}$ \\
\hline
\end{tabular}

Nota: Os resultados estão expressos como média \pm erro padrão da média. Análise por Kruskal-Wallis, seguido também pelo teste D'Agostino \& Pearson. Legenda: a $p<0,05$ comparado com grupo controle; ${ }^{b} p<0,05$ comparado com grupo imipramina (25 mg/kg). Fonte: Oliveira KM, et al., 2020.

\section{DISCUSSÃO}

O teste de campo aberto é o melhor teste comportamental para avaliar simultaneamente a atividade locomotora e respostas semelhantes a ansiedade (SHIEH KR e YANG SC, 2020). Um dos parâmetros analisados neste teste, é o Rearing, que é o ato de levantar-se com as duas patas traseiras (KOZLER P, 2017). Este parâmetro permite a avaliação da locomoção (vertical) do animal, de forma que quanto maior 0 número de Rearing indica uma possível atividade ansiolítica (KUNIISHI H, et al., 2017; STURMAN O, et al., 2018).

No presente estudo, ao avaliar o parâmetro Rearing, os animais tratados pela substância GA-4 não apresentaram um aumento significativo ao comparar com o grupo controle. Assim como, não apresentaram 
alterações com relação ao grupo que recebeu Imipramina, indicando, portanto, não se tratar de uma substância com atividade ansiolítica e sim com uma possível atividade antidepressora.

A imipramina é um antidepressivo tricíclico frequentemente utilizado na clínica para o tratamento da depressão (RAMIREZ K e SHERIDAN JF, 2016). Portanto, a imipramina é bastante utilizada em pesquisas relacionadas a depressão, servindo como controle positivo, para descoberta de novos antidepressivos (AHMED AF, et al., 2018; HUANG Y, et al., 2019).

O Grooming, refere-se ao comportamento de autolimpeza. É um parâmetro no qual permite uma avaliação da ansiedade do animal. Quanto maior a atitude de autolimpeza, indica estados de ansiedade (WANG B, et al., 2017; JHA P, et al., 2018). A autolimpeza está envolvida em processos fisiológicos normais, e é controlado por um circuito neural complexo. Sendo característica de diversos distúrbios neuropsiquiátricos quando a autolimpeza é realizada de forma anormal (KALUEFF AV, et al., 2016; JAMES OO, et al., 2017).

A substância GA-4 em todas as doses testadas não provocou nenhuma alteração significativa quanto ao Grooming realizado pelos animais, quando comparado com o grupo controle e com o grupo que recebeu a imipramina. Portanto, ao analisar este parâmetro do teste do campo aberto, a substância GA-4 não apresentou características de provocar ansiedade, assim como no estudo de Rearing.

O número de cruzamentos é um parâmetro que está relacionado à locomoção do animal (movimento horizontal). Alterações na locomoção podem indicar um distúrbio neurológico, e assim manifestar a função cerebral anormal (KRAEUTER AK, et al., 2019). Além de refletir a locomoção, o teste de número de cruzamentos também reflete as medidas de exploração e ansiedade (ZIMCIKOVA E, et al., 2017). A substância GA-4 não provocou nenhuma alteração quanto ao número de cruzamentos dos animais quando comparado com o grupo controle. Havendo apenas um aumento da ambulação dos grupos que receberam a dose de $50 \mathrm{mg} / \mathrm{Kg}$ e $200 \mathrm{mg} / \mathrm{Kg}$, quando comparados com o grupo que foi administrado a imipramina. Portanto, diante destes resultados, a substância GA-4 não é capaz de alterar a locomoção significativamente, indicando não ser uma substância psicoestimulante.

A ansiedade também está associada à atividade autonômica aumentada, resultando em aumento da defecação e micção (JHA P, et al., 2018). Além da ansiedade, o aumento de defecação sinaliza um possível processo depressivo do animal (BEE R e MAHESHWARI K, 2019). A substância GA-4 não provocou nenhuma alteração quanto a defecação dos animais. Quanto a micção, foi observada um aumento apenas nos animais que receberam a maior dose da substância GA-4. Sendo este o único parâmetro dentre todos os outros analizados do teste do campo aberto, que apresentou alguma alteração comparado com o grupo controle. Desta forma, não se pode a partir de um único resultado, afirmar que os animais estavam com ansiedade provocada pela substância em estudo.

O teste do campo aberto foi utilizado de forma discriminatória. No qual a partir deste, desvendamos que a substância em questão não se tratava de um psicoestimulante, tendo uma maior propensão para uma atividade antidepressora. Portanto, posteriormente ao teste de campo aberto, foi realizado o teste do nado forçado, para melhor evidenciar o efeito antidepressivo da substância GA-4.

De acordo com o teste do nado forçado, a substância GA-4 apresentou potencial efeito antidepressivo nas doses de 50 e $100 \mathrm{mg} / \mathrm{Kg}$. Já que nestas doses houve um menor tempo de imobilização ao comparar com o grupo controle. Já ao observarmos a maior dose testada, esta causou um aumento no tempo de imobilidade dos camundongos comparados com os grupos tratados por Imipramina $(25 \mathrm{mg} / \mathrm{Kg})$. O teste de nado forçado é um ensaio preditivo, bastante utilizado pela comunidade científica como meio para pesquisa de novos antidepressivos (KOKRAS N, et al., 2017; NAZ S, et al., 2017; SAKHAEE E, et al., 2016). Os animais expostos a este teste, assumem uma posição imóvel, na qual acredita-se demonstrar um estado de desespero comportamental. Assim, quanto maior o tempo de imobilidade, maior é o estado depressivo do animal (NAZARI SK et al., 2016).

A realização do teste de campo aberto é importante para respaldar o teste de nado forçado, e evitar resultado falso positivo (KHAN AW e KHAN AU, 2019). Pois, a realização do ensaio do campo aberto permite confirmar que a imobilidade durante o nado forçado não é devido a alteração na atividade locomotora dos animais (NAZARI SK, et al., 2016). 
A maioria dos antidepressivos causam a redução do tempo de imobilidade dos animais no teste de natação forçada (JIN QH, et al., 2020). Logo, a substância GA-4 pode ser classificada com uma possível atividade antidepressora, já que diminui o tempo de imobilidade no teste do nado forçado e não causou nenhuma alteração significativa quanto a locomoção nos testes de campo aberto.

Através do docking é possível sugerir um mecanismo de ação para a molécula estudada. Assim, foi identificado que a substância GA-4 foi capaz de ligar-se ao receptor a2- adrenérgico, com alta energia de ligação e no mesmo sítio ativo da ioimbina. Esta que é um antagonista deste receptor (YAPICI-ESER H et al., 2018). Portanto, possivelmente o mecanismo de ação da substância GA-4 está envolvido com a antagonização do receptor a2- adrenérgico, permitindo que ocorra liberação de noradrenalina, minimizando assim os efeitos depressivos.

Os agonistas do receptor $\alpha-2$ inibem a liberação de noradrenalina (NA) dos terminais noradrenérgicos, já os antagonistas do receptor a-2 têm um efeito oposto (YAPICI-ESER $\mathrm{H}$, et al., 2018). Evidências apontam que pacientes com transtorno depressivo maior apresentam uma regulação positiva dos receptores a2 centrais, o que leva à diminuição da atividade noradrenérgica (KUEHL LK, et al., 2020).

\section{CONCLUSÃO}

Diante dos resultados obtidos, pode-se concluir que a substância GA-4 é um potencial candidato a medicamento antidepressor. Tendo em vista que reduziu o tempo de imobilidade dos animais no teste do nado forçado. Além do que, não alterou na atividade locomotora dos animais, confirmando assim o teste do nado forçado. Assim como também através dos resultados de docking infere-se que esta molécula é um possível antagonista dos receptores a2- adrenérgico, o que justificaria seu efeito antidepressivo.

\section{REFERÊNCIAS}

1. AHMED AF, et al. Roles of $\beta$-adrenergic receptors on the mechanism of action of imipramine in chronic mild stress model of depression. Lebda Medical Journal, 2018; 5(1): 168-179.

2. ARCHER J. Tests for emotionality in rats and mice: a review. Animal Behaviour, 1973; 21 (2): 205-235.

3. BASHIR MA, et al. Synthesis, characterization, molecular docking evaluation, antidepressant, and anti-Alzheimer effects of dibenzylidene ketone derivatives. Drug development research, 2019; 80(5): 595-605.

4. BEE R e MAHESHWARI, KK. Evaluation of antidepressant activity of acyranthes aspera by using open field test in rats. World Jornal of Pharmaceutical Research, 2019; 8(1): 1183-1195.

5. COMMONS KG, et al. The Rodent Forced Swim Test Measures Stress-Coping Strategy, Not Depression-like Behavior. ACS Chem Neurosci, 2017; 8(5): 955-960.

6. DAWOOD S, et al. Docking studies of antidepressants against single crystal structure of tryptophan 2, 3-dioxygenase using Molegro Virtual Docker software. Pak J Pharm Sci, 2014; 27(5): 1529-1539.

7. GOMES MN, et al. Chalcone Derivatives: Promising Starting Points for Drug Design. Molecules, 2017; $22(8): 1-25$.

8. GUAN LP, et al. Evaluation of potential antidepressant-like activity of chalcone-1203 in various murine experimental depressant models. Neurochemical research, 2014; 39(2): 313-320.

9. JAMES OO, et al. Subchronic Amitriptyline Influences Open-field Behaviours and Spontaneous Working-memory in Healthy Mice. Advances in pharmacol and pharm, 2017; 5(1):1-11.

10. JHA P, et al. A comparative analysis of anxiolytic activity of Arnica montana and alprazolam in rats using open field test. International Journal of Basic \& Clinical Pharmacology, 2018; 7(4): 718-722.

11. JIN QH, et al. Synthesis and biological effects of naphthalene-chalcone derivatives. Medicinal Chemistry Research, 2020; 29(1): 1-10.

12. KALUEFF AV, et al. Neurobiology of rodent self-grooming and its value for translational neuroscience. Nature Reviews Neuroscience, 2016; 17(1): 45-59.

13. KHAN AW, KHAN AU. Antidepressant effect of solanum surattense burm. F. JAPS: Journal of Animal \& Plant Sciences, 2019; 29(4): 1188-1192.

14. KOKRAS N, et al. Head shaking in the forced swim test: a robust but unexplored sex difference. Pharmacology Biochemistry and Behavior, 2017; 152(1): 90-96.

15. KOZLER $P$, et al. Study of locomotion, rearing and grooming activity after single and/or concomitant lesions of central and peripheral nervous system in rats. Neuroendocrinology Letters, 2017; 38(7): 495-505.

16. KRAEUTER AK, et al. The open field test for measuring locomotor activity and anxiety-like behavior. In: Pre-Clinical Models. Humana Press, 2019; 1916: 99-103.

17. KUEHL LK, et al. Enhanced noradrenergic activity by yohimbine and differential fear conditioning in patients with major depression with and without adverse childhood experiences. Progress in Neuro-Psychopharmacology and Biological Psychiatry, 2020; 96: 109751. 
18. KUNIISHI H, et al. Early deprivation increases high-leaning behavior, a novel anxiety-like behavior, in the open field test in rats. Neuroscience research, 2017; 123(1): 27-35.

19. HALL CS. Emotional behavior in the rat. 1. defecation and urination as measures of individual differences in emotionality. Journal of Comparative Psychology, 1934; 18(1):382403

20. HAO Y, et al. Selecting an Appropriate Animal Model of Depression. International journal of molecular sciences, 2019; 20(19):4827.

21. HIGGS J, et al. Chalcone derivatives: synthesis, in vitro and in vivo evaluation of their anti-anxiety, anti-depression and analgesic effects. Heliyon, 2019; 5(3): 1-35.

22. HUANG Y, et al. Rapid antidepressant actions of imipramine potentiated by zinc through PKA-dependented regulation of mTOR and CREB signaling. Biochemical and biophysical research communications, 2019; 518(2): 337-343.

23. LEITE JR e SIQUEIRA JS. Métodos para avaliar drogas ansiolíticas. ALMEIDA RN, Psicofarmacologia: fundamentos práticos. 1를 Ed. Rio de Janeiro: Guanabara Koogan, 2006; 154-160.

24. MÉNARD C, et al. Pathogenesis of depression: Insights from human and rodent studies. Neuroscience, 2016; 321(1):138-162.

25. MONTGOMERY KC. The relation between fear induced by novel stimulation and exploratory drive. Journal of comparative and physiological psychology, 1955; 48(4): 254.

26. NAZ S, et al. Antidepressent Effect of Two New Benzyl Derivatives from Wild Strawberry Fragaria vesca var. nubicola Lindl. ex Hook. f. Frontiers in pharmacology, 2017; 8(1): 469.

27. NAZARI SK, et al. Possible involvement of ATP-sensitive potassium channels in the antidepressant-like effect of baclofen in mouse forced swimming test. Pharmacological Reports, 2016; 68(6): 1214-1220.

28. PAGADALA NS, et al. Software for molecular docking: a review. Biophysical reviews, 2017; 9(2): 91-102.

29. POLESZAK E, et al. Antidepressant-Like Activity of Typical Antidepressant Drugs in the Forced Swim Test and Tail Suspension Test in Mice Is Augmented by DMPX, an Adenosine $A_{2 A}$ Receptor Antagonist. Neurotoxicity research, 2019; 35(2): 344-352.

30. PORSOLT RD, et al. Behavioural despair in rats: a new model sensitive to antidepressant treatments. European Journal of Pharmacology,1978; 47(4): 379-391.

31. RAMIREZ K e SHERIDAN JF. Antidepressant imipramine diminishes stress-induced inflammation in the periphery and central nervous system and related anxiety-and depressive-like behaviors. Brain, behavior, and immunity, 2016; 57(1): 293-303.

32. SAKHAEE E, et al. The role of NMDA receptor and nitric oxide/cyclic guanosine monophosphate pathway in the antidepressant-like effect of dextromethorphan in mice forced swimming test and tail suspension test. Biomedicine \& Pharmacotherapy. 2017; 85(1): 627-634.

33. SHIEH KR e YANG SC. Formosan wood mice (Apodemus semotus) exhibit more exploratory behaviors and central dopaminergic activities than C57BL/6 mice in the open field test. Chinese Journal of Physiology, 2020; 63(1):27.

34. STURMAN O, et al. Exploratory rearing: a context-and stress-sensitive behavior recorded in the open-field test. Stress, 2018; $21(5):$ 443-452.

35. UNAL G e CANBEYLI R. Psychomotor retardation in depression: A critical measure of the forced swim test. Behavioural brain research, 2019; 372(1):112047.

36. WANG B, et al. Zfp462 deficiency causes anxiety-like behaviors with excessive self-grooming in mice. Genes, Brain and Behavior, 2017; 16(2): 296-307.

37. WANG J, et al. Prevalence of depression and depressive symptoms among outpatients: a systematic review and metaanalysis. BMJ open, 2017; 7(8): 1-14.

38. YAPICI-ESER H, et al. Stress modulates cortical excitability via $\alpha-2$ adrenergic and glucocorticoid receptors: As assessed by spreading depression. Experimental neurology, 2018, 307(1): 45-51.

39. ZHUANG C, et al. Chalcone: A Privileged Structure in Medicinal Chemistry. Chemical reviews, 2017; 117(12):77627810.

40. ZIMCIKOVA E, et al. Behavioral effects of antiepileptic drugs in rats: Are the effects on mood and behavior detectable in open-field test?.Seizure, 2017; 52(1): 35-40. 